\title{
Teachers' Feedback on a New Variety of English: The Case of Hong Kong English
}

\author{
Ka Long Roy CHAN ${ }^{1}$ \\ ${ }^{1}$ Department of English, The Hong Kong Polytechnic University, Hong Kong \\ Correspondence: Ka Long Roy CHAN, 4/F, Department of English, Chung Sze Yuen Building, The Hong Kong \\ Polytechnic University, Hunghom, Kowloon, Hong Kong. E-mail: roylongckl@gmail.com
}

Received: April 27, 2021; Accepted: May 25, 2021; Published: May 25, 2021

The research is self-financed by the Author.

\begin{abstract}
The present short report reveals how teachers of English in Hong Kong (HKTEs) react to Hong Kong English (HKE). By employing a mixed method approach consisting of 100 survey responses and 28 interviews, types of feedback and activities teachers use when they encounter HKE in classroom were recorded and reported. The results showed that the two types of teachers of English - Native and Non-native English speakers - provided different kinds of responses because of the differences in attitude they held toward new varieties of English. The current study potentially sheds light on how different varieties of English could fit in traditional ESL curricula. Further research is warranted on how the feedback may affect English acquisition among Hong Kong students and whether the feedback brings positive or negative effects to the students.
\end{abstract}

Keywords: World Englishes, Hong Kong English, English teaching, corrective feedback

\section{Introduction}

While the linguistic features of Hong Kong English (HKE), a rather new variety of English, have been investigated over the past two decades, little has been done on its application in ESL teaching, particularly teachers' reaction to the variety or teachers' education in new Englishes. Extensive research has been performed on HKE, in terms of its phonological inventories (e.g. Hansen Edwards, 2016, 2018; Hung, 2000; Lam, 2017), language attitudes (e.g. Chan, 2016/2017; Hansen Edwards, 2015, 2016; Zhang, 2014), sociolinguistic features (e.g. Chan, 2018, 2019) and intelligibility (e.g. Hansen Edwards et al., 2018; Sewell, 2012).

However, little research has examined how teachers of English, especially, those who are L2 speakers, react to these varieties of new Englishes. Generally, the study of World Englishes (WE), wherein different varieties of Englishes are investigated, espouses the view that English belongs to all English speakers, which is different from the traditional "native speaker" definition. For example, Hino (2018) proposes that localized English (like Japanese English) could be the native language of the Japanese according to a roadmap which includes a reformation of education policy and curriculum. Adopting Hiro's (2018) roadmap, Chan's (2020a) also proposes a similar roadmap for HKE to be the native language of Hongkongers. However, a reformation of the linguistic landscape requires teachers' cooperation in ESL teaching, especially their reactions to new varieties of English.

Before the design and implementation of these roadmaps, an understanding of how ESL teachers view and react to new varieties of English is essential. Owing to the limited literatures on teachers' feedback towards varieities of English, the current paper is hoped to answer the following question: How teachers of English in Hong Kong react to HKE? What are their preferences on the types of feedback and activities? Therefore, this short paper reports on the results of a mixed method survey (which is a part of a large research project investigating the teachers of English in Hong Kong) which was conducted to reveal the types of oral corrective feedback and the activity types that the teachers of English in Hong Kong (HKTEs) use when they are facing HKE in their classrooms. Also, it is also hoped to see whether different HKTEs (native and non-native) would provide different forms feedback and use different activities in English teaching.

\section{Literature Review}

The current project focuses on the types of corrective feedback (CFs) used by HKTEs; in this part, previous studies on classroom feedback, HKE, and the background of English teaching in Hong Kong will be briefly summarized. 


\subsection{Oral Corrective Feedback Types - Explicit and Implicit Feedback}

In Second Language Acquisition (SLA) studies, corrective feedback is considered as an important element in any classrooms as it provides students with significant inputs in their learning (Fan, 2020). Previous studies on oral CFs were normally on classroom observations, which identified how teachers provide feedback to students; among these studies, Lyster's and Ranta's (1997) identify six prominent types of oral feedback: recasts, clarification, elicitation, explicit correction, metalinguistic cues and repetition.

These CFs could also be divided into two major types - explicit and implicit, both of which "respond to 'errors' made by learners" (Han, 2010, p. 56) and provide information on the accuracy of learners' production (Leeman \& Martinez, 2007). When the teachers point out the errors covertly, they give implicit feedback whereas if they indicate the 'errors' overtly, they provide explicit feedback (Ellis, Loewen \& Erlam , 2006). Implicit feedback can take various forms; one of the most prevalent forms is recast, which refers to "a reformulation of an incorrect utterance that maintains the original meaning of the utterance" (Gass \& Selinker, 2008, p. 353); similarly, explicit feedback can be delivered in different forms, such as repetition and elicitation of the correct form (Han, 2010).

Tsang's (2004) investigation on oral CFs provided by teachers in Hong Kong suggested recasts and explicit corrections are the two most used CFs, echoing the results of Lyster and Ranta (1997), which stated that recasts and explicit correction were popular among teachers. This paper investigates the use of these CFs among HKTEs, with a special focus on how they react to HKE, which has rarely been studied before.

\subsection{English Teaching in Hong Kong and Hong Kong English}

English has been the official language of Hong Kong, an ex-British colony, for decades across myriad contexts, including government, business and education (Evans and Green, 2003). English is the compulsory subject in both primary schools (Grade 1 to 6) and secondary school (Grade 7-12) (Lo \& Lo, 2014) and serves as the medium of instruction (MOI) of nearly all universities in Hong Kong (Chan, 2020b).

Together with the 'bi-literacy and trilingual' policy in Hong Kong, students are expected to be trilingual. i.e., capable of reading written Chinese and English and speaking fluent Cantonese, English, and Mandarin (Chan, 2019). However, due to the contact between Cantonese and English, the English in Hong Kong, especially its phonological features, distinguishes it from the other varieties of English and has been identified as its own variety, HKE.

Previous studies have shown that the vowel inventories of HKE (e.g. Hung, 2000; Sung, 2015), consonant inventories (e.g. Hansen Edwards, 2015; Hung, 2000; Setter et al., 2010) and stress and intonation (Deterding et al., 2008; Lam, 2017) are significantly distinctive compared to other varieties of English. For example, HKE features a smaller set of vowel and consonant inventories and a syllable-stressed rhythm. Studies of HKE features have extended to other sociolinguistic matters, such as language attitudes (e.g. Chan, 2016/2017; Hansen Edwards, 2015, 2016; Sewell, 2012) and intelligibility (e.g. Chan, 2020a; Sewell, 2015). However, there has been a limited research on how HKE is perceived in an educational context.

Under the WE view, the unique inventory of HKE should be treated as features not errors (Hansen Edwards, 2016). However, while many have investigated the features of HKE, little focus has been given to how teachers view this type of English in the classroom. It is important to know how teachers view and react to a certain variety of English because they are the ones who implement the teaching duties; their feedback and the activities they use may affect the acquisition of the language (Crismore et al., 1996). Also, as mentioned earlier, the kind of CFs provided by teachers may help to determine whether HKE could be primarily introduced into teaching (Chan, 2020a). Therefore, in this paper, it is hoped that by figuring out the types of CFs as well as the activities that HKTEs use, a clearer picture could be seen how on teaching of HKE could be landed.

\section{Method}

The data of this mixed method study was derived from a small part of another study, in which both questionnaires and semi-structured interviews were conducted for data elicitation.

One hundred monolingual (English only) questionnaires were distributed and collected from HKTEs and twentyeight selected participants were chosen to join the semi-structured interviews. The HKTEs were recruited according to two factors: English "nativeness" (coded as NETs for Native English Teachers and LETs for Local English Teachers) and the level of institutes they teach (Primary, Secondary and Tertiary). Quantitative data were drawn from the questionnaires, which were finished by 100 in-service HKTEs (M: 40\%, F: 60\%; NET: 21\%, LET: 79\%; Primary: 32\%, Secondary: 39\%, Tertiary: 29\%); qualitative data were collected from the 800 -minute long interview data, which was transcribed verbatim, conduced with 28 HKTEs (M:46\%, F:54\%; NET: 25\%, LET: 75\%; Primary: $29 \%$, Secondary: $29 \%$, Tertiary: $42 \%$ ). 
While the larger number of questionnaires provides numerical data for data trend, the focus on a smaller number of interviews allowed for richer and complex descriptions to emerge (Hansen Edwards, 2017). Both the quantitative data and qualitative data were analyzed through descriptive statistics and thematic generation (Patton, 2015) to yield themes in response to the research questions.

\section{Findings and Discussion}

In this part, two themes were generated based on the results from the questionnaires and the interviews to answer the two research questions: the different use of CFs and the different use of activities for pronunciation teaching.

\subsection{Acceptance and Rejection of Using Hong Kong English}

Because this paper is concerned with the feedback on HKE, a relatively "newer" variety of English, the attitudes of HKTEs towards HKE were examined first. HKTEs were asked to rate the acceptability to HKE using a 6-point Likert-scale. The results showed that more than two-thirds of the HKTEs rated a 4 or above to HKE $(\overline{\mathrm{x}}: 4.15 ; \sigma$ : 1.49) (Table 1).

Table 1. The Acceptability of HKE among HKTEs

\begin{tabular}{lllllll}
\hline Acceptability & 1 (Lowest) & 2 & 3 & 4 & 5 & 6 (Highest) \\
\hline $\begin{array}{l}\text { Frequency } \\
(\mathrm{n}=100)\end{array}$ & 6 & 12 & 12 & 21 & 29 & 20 \\
\hline
\end{tabular}

This result suggests that HKTEs generally accept the use of HKE, which mirrors the result of several previous studies, like that of Chan (2019) and Hansen Edwards (2016). However, more than $80 \%$ of the HKTEs expressed that HKE is not a suitable variety of English in classroom because the examinations in Hong Kong do not accept HKE (62\%), HKE is a non-standard English (57\%) and HKE is only an error (40\%) (Table 2). Also, when it came to the types of CFs that HKTEs provided, $66 \%$ of the participants claimed they would not correct students directly unless in the context of an examination, while $32 \%$ of the HKTEs chose to give explicit feedback (correct them immediately) (Table 3).

Table 2. Reasons for not using HKE in Classrooms

\begin{tabular}{llll}
\hline & HKE is not accepted in Exams & HKE is not standard & HKE is an error \\
\cline { 2 - 4 }$\%$ & 62 & 57 & 40 \\
\hline
\end{tabular}

Table 3. Types of Corrective Feedback

\begin{tabular}{lll}
\hline & Would not correct (except exams) & Explicit Feedback \\
\cline { 2 - 3 }$\%$ & 62 & 57 \\
\hline
\end{tabular}

The results from the questionnaire showed that even though HKTEs generally acknowledge HKE, they refused the use of HKE in classrooms because HKE was neither accepted by the exam authority nor the standard, which is in line with the results of Groves (2011) and Zhang (2014), who discovered that Hongkongers have a high preference towards exonormative forms for English (like British or American English) over their own HKE. Chan (2020c) also suggested that the over emphasis on standard English in the curriculum may trigger a washback effect in education, leading to a discouragement in the use of local English.

The interview data provided details to support the findings from the questionnaires. Several LETs expressed that they would correct them directly, regardless of the level of institutes that they teach. Below are some excerpts from the interviews:

*Danny: 'If there's an examination, I would give them explicit feedback...during informal situation, I will just let them speak HKE.' [LET - Primary School Teacher]

*Mark: ‘...(I) do correct them, I would ask them to say it again... as a teacher, I do not allow that (the error). [LET - Secondary School Teacher] 
*Paul: 'I tell them the correct pronunciation or the correct answer, but I never stop them, I just let them finish first. (...) for pronunciation, I think it's (the feedback) very straightforward, "Oh, this is wrong, you should say...", [LET - University Lecturer]

*Susan: 'I do try to give explicit feedback; sometimes it's the tense problems or subject-verb agreement or the use of preposition, I would point it out.' [LET - University Lecturer]

The data reflect that most LETs offer explicit feedback, especially in formal situations, like examinations or graded presentations. However, none of the NETs in the current study expressed they would provide explicit feedback; instead, most of them would just encourage the students to speak more, in general:

*Polly: 'I don't think there's a necessarily a right or wrong issue...to me I think the most important thing is they know what they are doing and they can pick and choose (the words) in the right context' [NET - Secondary School Teacher]

*Cay: '...I am not referring to accuracy because to me, accuracy is not that important...communication is the major part of the language...I wouldn't do anything (...) I just want them to be able to communicate clearly.' [NET - University Lecturer]

The NETs clearly showed a different tendency on feedback type given; they are more receptive to the features that their students present through their English variety (in this case, HKE); however, LETs are more likely to give explicit feedback to correct the students directly, according to exonormative rather than the endonormative conventions. The results also raised another issue: the washback effect from the local examination systems (cf. Chan, 2020c). The LETs mentioned examinations extensively as the public university entrance examination (Hong Kong Diploma of Secondary Education Examinations - HKDSE) is still based on an exonormative norm (mostly British English due to the colonial background of Hong Kong). HKTEs, therefore, are very likely to correct students from the endonomative variety to the exonormative, i.e., British English.

\subsection{Explicit and Implicit Activities}

The results showed that LETs and NETs used different forms of activities, which can be categorized as both explicit and implicit. In the interview, the HKTEs were asked to provide the types of activities they normally used in class for pronunciation teaching. Surprisingly, of the 20 LETs, 14 of them (70\%) reported the use of explicit teaching activities regardless of level of institutes; for example, they attested to teaching individual sounds/vowels/ consonants using either phonics or International Phonetics Alphabets (IPA), or reading aloud with immediate correction of sounds. However, all of the NETs interviewed said they typically used methods like story-telling, songs, or even drama to teach English, all of which are classified as implicit teaching activities. Interestingly, LETs revealed that in Hong Kong, the instruction oral communication was mostly the job of NETs not LETs:

*Mary: 'We (LETs) always work with our NETs in oral lessons. He is responsible for teaching students to speak...(and) pronunciation, ideas elaborations, and how to express themselves and give them (the students) chances to speak, because he's the only NET, the only foreigner in the school.' [LET - Secondary School Teacher]

*Carly: '... in the university, I referred my students to see the adviser, the pronunciation adviser in the "Self-access Centre", so basically they are native English speakers, and then I sent my students there to ask for advice (on pronunciation) or sometimes just to practice with them.' [LET - University Lecturer]

The explicit teaching of individual sounds (either consonants or vowels) was recorded across different level of institutes and was mostly used by LETs. Different mediations were also mentioned, such as, flash cards, textbooks, computers, self-learning materials, etc. The following are the excerpts of some of the explicit teaching activities:

*May: 'if I find that they (the students) have problems with some pronunciation ...I will list them out and just directly teach the sounds that they require.' [LET - Secondary School Teacher] 
*Doreen: "we have a book called "Ship and Sheep" and we stick to that, and we teach the vowels, consonants, diphthongs.' [LET - Secondary School Teacher]

*Yvette: 'I'll try to teach them how to pronounce certain vowels (and) how vowels function...we have these kinds of like, recording labs, we record our own voice or sometimes I just read it like in class, like certain words or even just the vowels, and then they can record their own speaking into the system, so I can comment on how they are actually speaking the words.' [LET - Teacher in Tertiary Institute]

*Gigi: 'Actually in that lesson I show the vowel chart (and) the position of the tongue. I actually tell them like you will have to put your tongue here and there and I will just demonstrate to ... I also search for some Youtube links and I encourage them.' [LET - University Lecturer]

*Carly: 'I directed them to the in-house self-developed software in the university, so that they could also listen, record and try to improve their pronunciation.' [LET - University Lecturer]

From the above excerpts, it can be concluded that LETs and NETs use different methods in pronunciation teaching. While the NETs generally use interactive methods with the help of implicit feedback, the LETs provide explicit teaching of individual sounds and explicit correction on pronunciation.

\section{Conclusion}

The current short report presents part of the data from a larger project and reveals how the HKTEs view HKE. The mixed method study shows that, in general, LETs provide explicit feedback to their students with the use of explicit teaching methods like direct teaching of sounds whereas NETs prefer implicit feedback, like the use of recasts, with the use of implicit teaching methods, such as dramas and story-telling.

The result of this study is potentially significant to the discussion of how different Englishes could fit into regional ESL curricula. However, with the limited number of participants and the rather restricted set of questions in the present study, many of the CFs types used by HKTEs are still in question, especially in terms of the contexts in which they use CFs, in addition to the exact forms of CFs they use.

Because the present study is only an initial attempt to report on the current situations of English teaching in Hong Kong, further investigation should focus on how teachers of English react to different varieties of Englishes, especially how their teaching practice is shaped by their attitudes towards the Englishes.

\section{References}

Chan, K. L. R. (2016/2017). Attitudes towards Hong Kong English: Native English teachers and local English teachers. Asian Journal of English Language Teaching, 26, 85-110.

Chan, K. L. R. (2018). Being a 'purist' in trilingual Hong Kong: Code-switching among Cantonese, English and Putonghua. Linguistic Research, 35(1), 75-95. https://doi.org/10.17250/khisli.35.1.201803.003

Chan, K. L. R. (2019). Trilingual Code-switching in Hong Kong. Applied Linguistics Research Journal, 3(4), 114. https://doi.org/10.14744/alrj.2019.22932ALR

Chan, K. L. R. (2020a). The Intelligibility of the Segmental and Suprasegmental Features of Hong Kong English to Listeners in the Inner, Outer, and Expanding Circles [Ph.D. Thesis]. The Chinese University of Hong Kong.

Chan, K. L. R. (2020b). The future of Hong Kong English: Codification and standardisation. In W. Tang (Ed.), Hong Kong: Past, Present and Future (pp. 69-88). Nova Science.

Chan, K. L. R. (2020c). Washback in education: A critical review and its implications for language teachers. Journal of Foreign Language Education and Technology, 5(1), 108-124.

Crismore, A., Ngeow, K. Y. H., \& Soo, K. S. (1996). Attitudes towards English in Malaysia. World Englishes, 15(3), 319-335. https://doi.org/10.1111/j.1467-971X.1996.tb00118.x

Deterding, D., Wong, J., \& Kirkpatrick, A. (2008). The pronunciation of Hong Kong English. English World-Wide, 29(2), 148-175. https://doi.org/10.1075/eww.29.2.03det

Ellis, R., Loewen, S., \& Erlam, R. (2006). Implicit and explicit corrective feedback and the acquisition of L2 grammar. Studies in Second Language Acquisition, 28, 339-368. 
https://doi.org/10.1017/S0272263106060141

Evans, S., \& Green, C. (2003). The use of English by Chinese professionals in post-1997 Hong Kong. Journal of Multilingual and Multicultural Development, 24(5), 386-412. https://doi.org/10.1080/01434630308666507

Han, Y. (2000). The Effect of Implicit and Explicit Feedback [PhD. Thesis]. University of Florida: Flordia.

Hansen Edwards, J. G. (2015). Hong Kong English: Attitudes, identity, and use. Asian Englishes, 17(3), 184-208. https://doi.org/10.1080/13488678.2015.1049840.

Hansen Edwards, J. G. (2016). The deletion of /t, d/ in Hong Kong English. World Englishes, 35(1), 60-77. https://doi.org/10.1111/weng.12166

Hansen Edwards, J. G. (2017). English language schooling, linguistic realities, and the native speaker of English in Hong Kong. Multilingua: Journal of Cross-Cultural and Interlanguage Communication, 37(3), 275-304. https://doi.org/10.1515/multi-2016-0012

Hansen Edwards, J. G. (2018). TH variation in Hong Kong English. English Language and Linguistics, 23(2), 439-468. https://doi.org/10.1017/S1360674318000035

Hansen Edwards, J. G., Zampini, M. L. \& Cummingham, C. (2018). The accentedness, comprehensibility, and intelligibility of Asian Englishes. World Englishes, 37(4), 538-557. https://doi.org/10.1111/weng.12344

Hino, N. (2018). EIL education for the expanding circle: A Japanese model. Routledge.

Hung, T. T. N. (2000). Towards a phonology of Hong Kong English. World Englishes, 19(3), 337-356. https://doi.org/10.1111/1467-971X.00183

Lam, T. (2017). Intonational variation in Hong Kong English: A pilot study. Asian Englishes, 19(1), 22-43. https://doi.org/10.1080/13488678.2016.1277411

Leeman, J., \& Martinez, G. (2007). From identity to commodity: Ideologies of Spanish in heritage language textbooks. Critical Inquiry in Language Studies, 4, 35-65. https://doi.org/10.1080/15427580701340741

Lo, Y. Y., \& Lo, E. S. C. (2014). A meta-analysis of the effectiveness of English-medium education in Hong Kong. Review of Educational Research, 84(1), 47-73. https://doi.org/10.3102/0034654313499615

Lyster, R., \& Ranta, L. (1997). Corrective feedback and learner uptake. Studies in Second Language Acquisition, 19, 37-66. https://doi.org/10.1017/S0272263197001034

Patton, M. Q. (2015). Qualitative Research and Evaluation Methods (4 ${ }^{\text {th }}$ Ed.). SAGE.

Setter, J., Wong, C., \& Chan, B. (2010). Hong Kong English. Edinburgh University Press.

Sewell, A. (2012). The Hong Kong English accent: Variation and acceptability. Hong Kong Journal of Applied Linguistics, 13(2), 1-21.

Sewell, A. (2015). The intranational intelligibility of Hong Kong English accents. System, 49, 86-97. https://doi.org/10.1016/j.system.2015.01.003

Sung, C. C. M. (2015). Hong Kong English: Linguistic and sociolinguistic perspectives. Language and Linguistics Compass, 9(6), 256-270. https://doi.org/10.1111/lnc3.12142

Tsang, W. (2004). Feedback and uptake in teacher-student interaction: An analysis of 18 English lessons in Hong Kong secondary classrooms. Regional Language Centre Journal, 35, 187-209. https://doi.org/10.1177\%2F003368820403500207

Zhang, Q. (2014). Investigating Hong Kong English. Peter Lang.

\section{Copyrights}

Copyright for this article is retained by the author(s), with first publication rights granted to the journal.

This is an open-access article distributed under the terms and conditions of the Creative Commons Attribution license (http://creativecommons.org/licenses/by/4.0/). 